\title{
Proliferation, Differentiation and Immunoregulatory Capacities of Brown and White Adipose-Derived Stem Cells from Young and Aged Mice
}

\author{
Yan-Mei Yang ${ }^{1}$, Xiao-Hui Dong', Wei-Chao $\mathrm{Ma}^{2}$, Li-Hui Guan ${ }^{3}$, Yu-Han Wang ${ }^{2}$, \\ Xiao-Hui Huang, Jun-Feng Chen ${ }^{2}$, Xin Zhao ${ }^{2}$, Shi-Ming Yang ${ }^{4}$, Xiao-Xia Jiang ${ }^{2}$, Ning Wen ${ }^{1}$ \\ ${ }^{1}$ Department of Stomatology, The First Medical Centre, Chinese PLA General Hospital, Beijing, China \\ ${ }^{2}$ Department of Neural Engineering and Biological Interdisciplinary Studies, Institute of Military Cognition and Brain Sciences, \\ Academy of Military Medical Sciences, Beijing, China \\ ${ }^{3}$ Department of Animal Husbandry Engineering, College of Animal Science and Technology, Hebei North University, Zhangiakou, China \\ ${ }^{4}$ Department of Otolaryngology, Head \& Neck Surgery, The First Medical Centre, Chinese PLA General Hospital, Beijing, China
}

Background and Objectives: Adipose tissue is a source of mesenchymal stem cells, which have the potential to differentiate into various types of cells. Adipose-derived stem cells (ADSCs) are now recognized as an accessible, abundant, and reliable stem cells suitable for tissue engineering and regenerative medicine applications. However, few literatures gave a comprehensive report on the capacities of ADSCs harvested from different sites. Especially, the capacities of ADSCs from aged mice remained unclear. In this study, we investigated several main capacities of brown adipose derived stem cells (B-ADSCs) and white adipose derived stem cells (W-ADSCs) from both young and aged mice. Methods and Results: When isolated from young mice, B-ADSCs showed a stronger proliferation rate and higher osteogenic, adipogenic and myocardial differentiation ability than W-ADSCs. Carboxy fluorescein diacetate succinimidyl ester (CFSE) labeling test suggested no significant difference in immunosuppression capacity between B-ADSCs and W-ADSCs. Similarly, no difference between these two were found in several immune related molecules, such as programmed death-ligand 1 (PD-L1), intercellular cell adhesion molecule (ICAM-1), vascular cell adhesion molecule (VCAM-1), inducible nitric oxide synthase (iNOS), tumour necrosis factor- $\alpha$ (TNF- $\alpha$ ), interleukin 10 (IL10), and suppressor of cytokine signaling 1 (socsl). When isolated from aged mice, B-ADSCs also showed a stronger proliferation rate and higher osteogenic, adipogenic and myocardial differentiation ability than W-ADSCs; however, it demonstrated an attenuated immunosuppression capacity compared to W-ADSCs.

Conclusions: In summary, our data showed that ADSCs' characteristics were tissue source dependent and changed with age. It provided evidence for choosing the right tissue-specific ADSCs for clinical application and fundamental research.

Keywords: Brown adipose derived stem cells, White adipose derived stem cells, Differentiation, Immunoregulation, Aged mice

Received: January 20, 2020, Revised: March 14, 2020, Accepted: March 20, 2020, Published online: April 30, 2020

Correspondence to Ning Wen

Department of Stomatology, The First Medical Centre, Chinese PLA General Hospital, 28 Fuxing Road, Haidian District, Beijing 100853, China

Tel: +86-010-66937179, Fax: +86-010-66937179, E-mail: wenningchn@163.com

Co-Correspondence to Xiao-Xia Jiang

Department of Neural Engineering and Biological Interdisciplinary Studies, Institute of Military Cognition and Brain Sciences, Academy of Military Medical Sciences, 27 Taiping Road, Haidian District, Beijing 100850, China

Tel: +86-18610049161, Fax: +86-10-68166874, E-mail: smilovjiang@163.com

다 This is an open-access article distributed under the terms of the Creative Commons Attribution Non-Commercial License (http://creativecommons.org/licenses/by-nc/4.0/), which permits unrestricted non-commercial use, distribution, and reproduction in any medium, provided the original work is properly cited.

Copyright (c) 2020 by the Korean Society for Stem Cell Research 


\section{Introduction}

Stem cells are characterized by their ability to self-renew and to differentiate along multiple lineage pathways. Therefore, they have significant potential in tissue engineering and regenerative medicine. Since the 1970s, mesenchymal stem cells (MSCs) have received growing interests, attracting an increasing number of people to study their extensive self-renewal, differentiation potential (1) as well as their immunoregulation capability (2-7). Though MSCs were first isolated and cultured from the bone marrow (8), they have since been harvested from many other organs and tissues, including adipose tissue (9), umbilical cord (10), placenta (11), skin (12), muscle tissue (13), neuronal tissue (14), and dental pulp (15). While MSCs derived from bone marrow (BM-MSCs) continue to be the research hotspot, adipose tissue yields about 500-fold greater MSCs than bone marrow with the same quality (16). In addition, adipose-derived stem cells (ADSCs) can be easily isolated from a number of adipose tissues and then expand in abundance ex vivo. Also, ADSCs can differentiate into adipocytes, myocytes, chondrocytes, and osteoblasts (9), and share similar surface markers with BM-MSCs (17). What's more, ADSCs do not lead to adverse side effects, such as tumorigenicity, chromosomal abnormalities, or immune rejection (18). Aforementioned characteristics make ADSCs attractive candidate for use in clinical therapy and fundamental research.

Two types of adipose tissue are known in mammals, namely white adipose tissue (WAT) and brown adipose tissue (BAT). WAT is widely distributed in subcutaneous tissues and visceral fat surrounding organs throughout the body. WAT's function is to store the excess energy into form of fat. In contrast, BAT is only observed in limited parts of body, such as interscapular, axillary, and perirenal region, and it disappears from most of these areas with age. BAT is specialized in energy expenditure, and it plays an important role in maintaining body temperature and energy balance (19). However, the differences between ADSCs from BAT (B-ADSCs) and ADSCs from WAT (W-ADSCs) are not well known. Only a few literatures revealed the differentiation of B-ADSCs and W-ADSCs (20), but the difference of their immunoregulation capacity is still unclear. Especially, it's still unknown whether the capacities of B-ADSCs and W-ADSCs will change as age increases. Therefore, in this study, we provide a general comparison between B-ADSCs and W-ADSCs from both young and aged mice in their isolation and expansion, proliferation and differentiation, and immunoregulation capacities. The comparative study intends to provide the basis for the choice of ADSCs in clinical application and fundamental research.

\section{Materials and Methods}

\section{Animals}

Healthy C57BL/6 mice (3 4 weeks and 7 8 months) were obtained from the Laboratory Animal Center of the Academy of Military Medical Sciences of China (Beijing). All experiments were performed in accordance with the Academy of Military Medical Sciences Guide for Laboratory Animals. Additional approval was granted by the Animal Care and Use Committee of Beijing Institute of Basic Medical Sciences, with the approval number BMS-12021103.

\section{Isolation and expansion of B-ADSCs and W-ADSCs}

C57BL/6 mice (3 4 weeks and 7 8 months) were euthanized by cervical dislocation and sterilized in $75 \%$ ethanol for 5 minutes. B-ADSCs were isolated from interscapular adipose tissue with dorsal side facing up, and W-ADSCs were obtained from inguinal subcutaneous adipose tissue with abdomen facing up (21). Then tissue was rinsed with phosphate buffered saline (PBS), minced, and followed by digestion with $1 \mathrm{mg} / \mathrm{ml}$ collagenase type IV (Sigma-Aldrich) and $1 \mathrm{mg} / \mathrm{ml}$ dispase (Sigma-Aldrich) for 35 minutes at $37^{\circ} \mathrm{C}$ with agitation. To stop digestion, cells were added to $\alpha$-MEM medium (Gibco, Carlsbad, CA) containing 10\% FBS (Gibco) - and then filtered through a $40 \mu \mathrm{m}$ cell strainer (Biologix, USA) to generate singlecell suspensions. After centrifugation at $400 \mathrm{~g}$ for $5 \mathrm{mi}-$ nutes, cells were re-suspended in $\alpha$-MEM - containing $10 \% \mathrm{FBS}$ - at $37^{\circ} \mathrm{C}$ in $5 \% \mathrm{CO}_{2}$. When they reached $80 \sim$ $90 \%$ confluence, cells were sub-cultured in a ratio of $1: 3$.

\section{Proliferation and differentiation of ADSCs}

For cell proliferation, cells were seeded in a 24-well plate at the density of $1 \times 10^{4}$ cells per well in cultured medium. Cells were counted every two days for 8 days. The mean cell number was calculated for each triplicate. For differentiation, passage 3 (P3) cells were seeded in a 24-well plate at the density of $1 \times 10^{4}$ cells per well overnight. They were then induced with two media: one osteogenic induction medium, which contains $0.1 \mathrm{mM}$ dexamethasome, $50 \mathrm{mM}$ ascorbate-2 phosphate, $10 \mathrm{mM}$ glycerophosphate (Sigma-Aldrich); and the other adipogenic induction medium, which contains $1 \mathrm{mM}$ dexamethasone, $200 \mathrm{mM}$ indomethacin, $0.5 \mathrm{mM}$ 3-isobutyl1-methyl-xanthine, and $10 \mu \mathrm{g} / \mathrm{ml}$ insulin (Sigma-Aldrich). In vitro osteogenesis, cells were cultured for $0,3,7,10$ days, and then stained for alkaline phosphatase (ALP) ac- 
tivity, using the alkaline phosphatase kit (Sigma-Aldrich). In vitro adipogenesis, cells were cultured for $0,3,7,10$ days, and then stained for fat droplets, using the Oil-Red-O (Sigma-Aldrich). In addition, P1 cells were seeded in a 24-well plate at the density of $1 \times 10^{4}$ cells per well on carbon nanotube (CNT) for 3 days, and were analyzed for the expression of cardiac troponin $\mathrm{T}$ (cTnT), GATA4, and Nkx2.5 by qRT-PCR.

\section{Carboxy fluorescein diacetate succinimidyl ester labeling}

Peripheral $\mathrm{CD}^{+}$and $\mathrm{CD} 4{ }^{+} \mathrm{T}$ cells were selected with CD3e and CD4 MicroBead Kit (Miltenyi Biotec, Bergisch Gladbach, Germany) from spleens of adult C57BL/6 mice, and then labeled with $5 \mu \mathrm{M}$ carboxy fluorescein diacetate succinimidyl ester (CFSE, Invitrogen, Carlsbad, CA, USA) for 7 minutes at $4^{\circ} \mathrm{C}$. Labeling was terminated according to the manufacturer's protocol. After washing, cells were activated with $50 \mathrm{ng} / \mathrm{ml}$ phorbol myristate acetate (PMA) and $1 \mu \mathrm{g} / \mathrm{ml}$ ionomycin (Sigma-Aldrich) for 16 hours, and then co-cultured with or without B-ADSCs and W-ADSCs for 48 hours. Cell division, as indicated by reduction of fluorescence intensity, was analyzed by flow cytometry.

\section{Flow cytometry}

P3 cells $\left(1 \times 10^{5}\right.$ cells $)$ were suspended in $100 \mu 1$ PBS and labeled with antibody of surface marker with the following: CD29, CD31, CD45, CD86, Sca-1, and MHC II. Cells cultured with stimulation of $0 \mathrm{ng} / \mathrm{ml}, 2 \mathrm{ng} / \mathrm{ml}, 5$ $\mathrm{ng} / \mathrm{ml}, 10 \mathrm{ng} / \mathrm{ml} \mathrm{TNF}-\alpha$ and IFN- $\gamma$ for 12 hours, and were labeled with antibody of programmed death-ligand 1
(PD-L1), intercellular cell adhesion molecule (ICAM-1), and vascular cell adhesion molecule (VCAM-1) for $30 \mathrm{mi}-$ nutes at $4^{\circ} \mathrm{C}$. Cells were then washed with PBS and fixed with $1 \%$ paraformaldehyde and detected by using flow cytometry. All antibodies were purchased from BD or eBioscience.

\section{Quantitative RT-PCR}

Total RNA was extracted with TRIZOL (Sigma-Aldrich) and reverse transcribed into cDNA with a reverse transcriptase kit (Takara). cDNA was used as a template in real-time PCR with SYBR Green reagent from TOYOBO to determine specific gene expression. Primer sequences were presented in Table 1, and qRT-PCR was performed with the following conditions: $95^{\circ} \mathrm{C}$ for 3 minutes; $40 \mathrm{cy}-$ cles: $95^{\circ} \mathrm{C}$ for 15 seconds, $60^{\circ} \mathrm{C}$ for 15 seconds, $72^{\circ} \mathrm{C}$ for 15 seconds. It was then followed by melting curve analysis.

\section{Statistical analysis}

All data were analyzed with Prism 5.0 software (GraphPad Software, CA, USA) and are presented as the mean \pm S.D. Statistical significance was assessed by unpaired two-tailed Student's t-tests. p-value less than 0.05 were considered significant. Experiments were performed in triplicate.

\section{Results}

Similar morphological and phenotypic characteristics of B-ADSCs and W-ADSCs

B-ADSCs and W-ADSCs were spindle-shaped and fi-

Table 1. Mouse primer sequences

\begin{tabular}{|c|c|c|}
\hline \multirow{2}{*}{ Target gene } & \multicolumn{2}{|c|}{ Primer sequences } \\
\hline & Forward & Reverse \\
\hline GAPDH & 5'-ACAATGAATACGGCTACAG-3' & 5'-GTCCAGGGTTTCTTACTC-3' \\
\hline TNF- $\alpha$ & 5'-GATGGGTTGTACCTTGTCTACT-3' & 5'-CTTTCTCCTGGTATGAGATAGC-3' \\
\hline IL-10 & 5'-CCAAGCCTTATCGGAAATGA-3' & 5'-TCTCACCCAGGGAATTCAAA-3' \\
\hline iNOS & 5'-CAGCTGGGCTGTACAAACCTT-3' & 5'-CATTGGAAGTGAAGCGTTTCG-3' \\
\hline socs1 & 5'-CAACGGAACTGCTTCTTC-3' & 5'-AAGGCAGTCGAAGGTCTC-3' \\
\hline ALP & 5'-GGGCAATGAGGTCACATCCA-3' & 5'-GTGGTTCACCCGAGTGGTAG-3' \\
\hline Osterix & 5'-АСТСАТСССТАTGGCTCGTG-3' & 5'-GGTAGGGAGCTGGGTTAAGG-3' \\
\hline Ocn & 5'-GGGCAATAAGGTAGTGAACA-3' & 5'-GTCTTCAAGCCATACTGGTC-3' \\
\hline Runx2 & 5'-CCACAAGGACAGAGTCAGAT-3' & 5'-GATAGGAGGGGTAAGACTGG-3 \\
\hline Ppar- $\gamma$ & 5'-TTGATTTCTCСАGСАТТTCT-3' & 5'-GCACTTTGGTATTCTTGGAG-3' \\
\hline Cebp- $\alpha$ & 5'-CAAGAACAGCAACGAGTACCG-3' & 5'-GTCACTGGTCAACTCCAGCAC-3' \\
\hline Fabp4 & 5'-ACACCGAGATTTCCTTCAAACTG-3' & 5'-CСATCTAGGGTTATGATGCTCTTCA-3' \\
\hline cTnT & 5'-AGTTTAAGCGGCCСАСССТC-3' & 5'-TTCTTGCGCCAGTCTCCCAC-3' \\
\hline GATA4 & 5'-CTGGAAGACACСССАATCTC-3' & 5'-CСАTCTCGССТCСАGAGT-3' \\
\hline Nkx2.5 & 5'-GGCAGTGATGACCTGGAGTT-3' & 5'-TGGTTGGAGGTGACTTTGTG-3' \\
\hline
\end{tabular}


broblast-like in appearance 3 days after their isolation, and were spiral-shaped morphology when they reached $80 \sim 90 \%$ confluence. After continuous passage, cell morphology of both B-ADSCs and W-ADSCs became larger at P5 (Fig. 1A). These two ADSCs from young mice (3 4 weeks) were then analyzed for cell surface molecule expression: positive for the MSC markers Sca-1 and CD29, but negative for the haematopoietic and endothelial markers CD45, CD31, and MHC class II (Fig. 1B). Meanwhile, B-ADSCs and W-ADSCs from aged mice (7 8 months) expressed the same cell surface marker (Fig. 1C). These results indicate that B-ADSCs and W-ADSCs exhibited similar morphology and immunophenotype.

\section{B-ADSCs showed stronger proliferation capacity than W-ADSCs}

Next, we examined the proliferation of B-ADSCs and W-ADSCs from young mice ( $3 \sim 4$ weeks) by cell counting assay and cell-cycle phase testing. In the cell counting assay, cells were counted every two days for 8 days. We found proliferation of B-ADSCs was faster than that of
W-ADSCs especially at the fourth day (Fig. 2A). In addition, we analyzed the cell-cycle phase via propidium iodide (PI) staining by flow cytometry. We found a higher proportion of B-ADSCs in G2/S phase and a lower proportion in G0/G1 phase than those of W-ADSCs (Fig. 2B). The same result about cell-cycle phase was obtained in ADSCs of aged mice ( $7 \sim 8$ months) (Fig. 2C).

\section{Stronger osteogenic and adipogenic differentiation capacities of B-ADSCs compared with W-ADSCs}

As previously reported, ADSCs could differentiate into adipocytes and osteoblasts in vitro when cultured under appropriate conditions (9). Our results showed that BADSCs displayed stronger osteogenic and adipogenic differentiation ability. ALP staining and oil drops of B-ADSCs were much more than those of W-ADSCs (Fig. $3 \mathrm{~A}$ and $3 \mathrm{C}$ ). These significant augment in osteogenesis and adipogenesis were further observed through the analyses of Runx2, Alp, Ocn, Osterix, Ppar- $\gamma$, Cebp- $\alpha$, and Fabp4 mRNA expression levels (Fig. 3B and 3D). Additionally, in aged mice, osteogenesis and adipogenesis capaci-
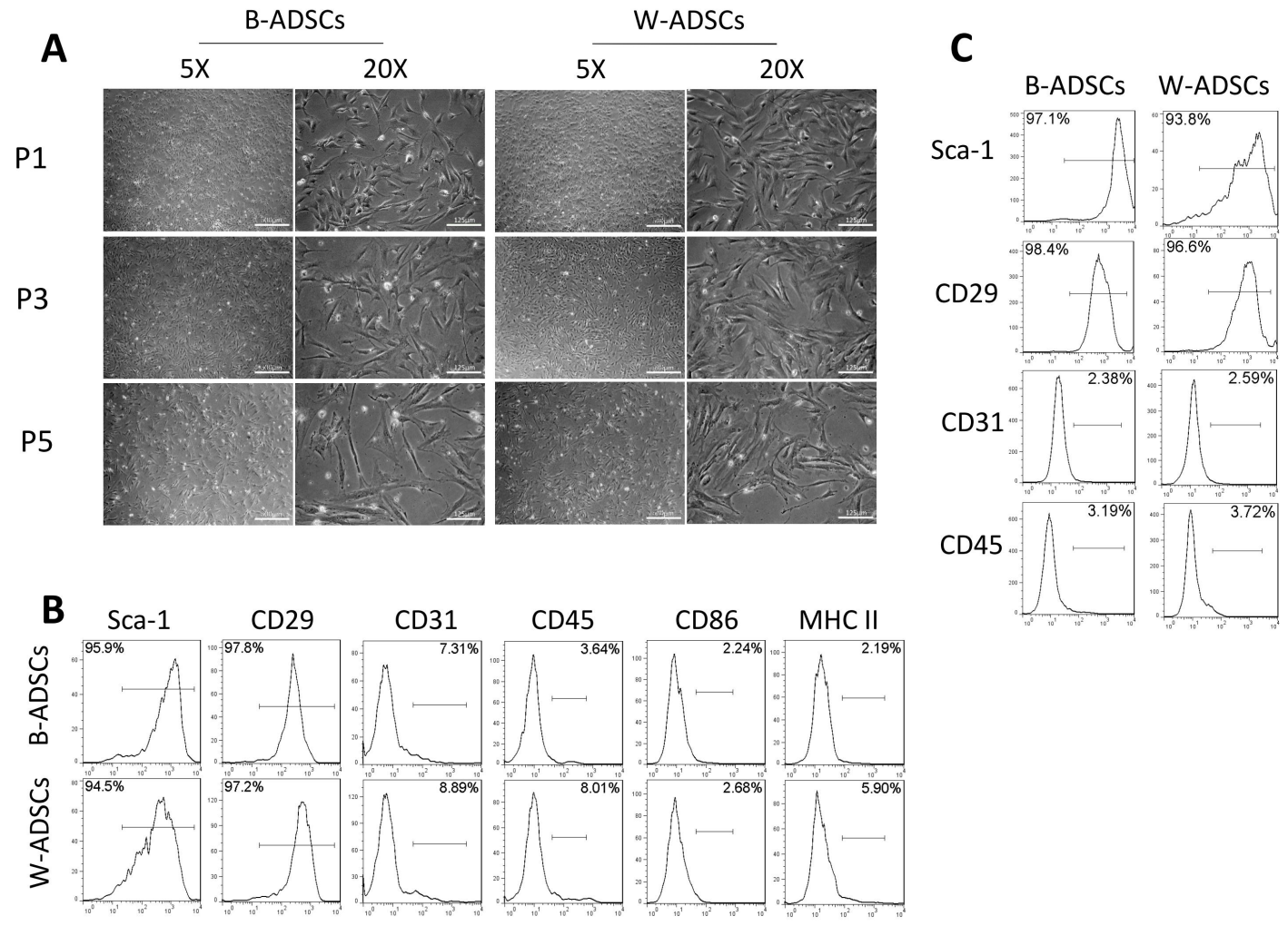

Fig. 1. Morphological and phenotypic characteristics of B-ADSC and W-ADSC. (A) Morphology of cultured B-ADSC and W-ADSC of P1, P3, P5 of 3-to-4-week C57BL/6 mice were analyzed by microscopy; each experiment was observed three fields. Cell surface markers of 3-to-4-week C57BL/6 mice (B) and of 7-to-8-month C57BL/6 mice (C) were analyzed by flow cytometry. Scale bars represent $500 \mu \mathrm{m}$ in the first and the third columns, and $125 \mu \mathrm{m}$ in the second and the fourth columns. 
A

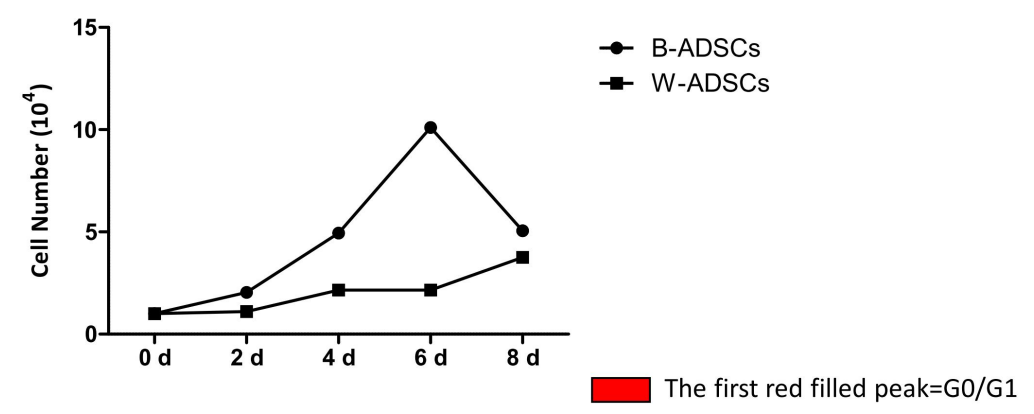

\section{B}
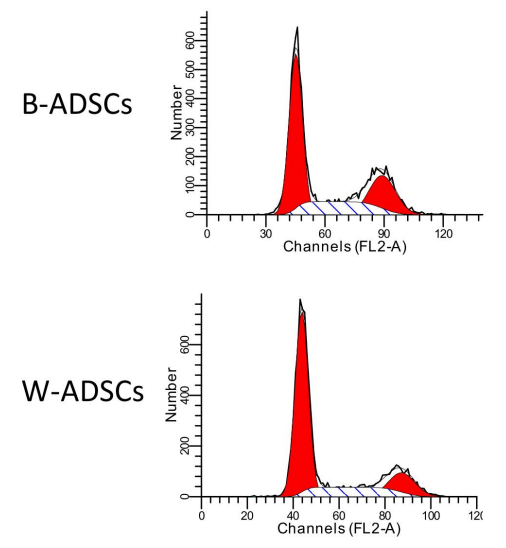

C

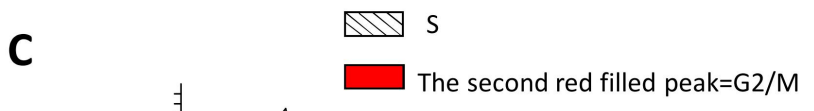

B-ADSCs

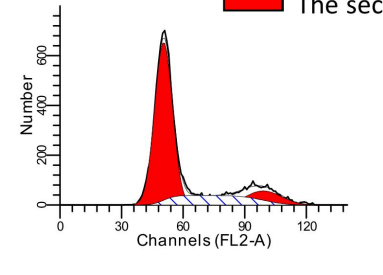

W-ADSCs

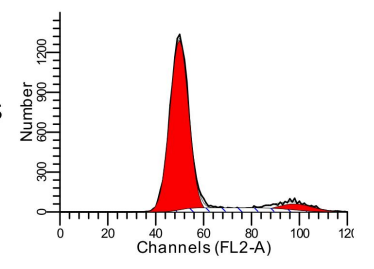

Fig. 2. Proliferation and cell-cycle phase of B-ADSC and W-ADSC. (A) The cell proliferation curve was made by cell counting every two days for 8 days. PI staining of 3-to-4-week C57BL/6 mice (B) and 7-to-8-month C57BL/6 mice (C) were analyzed by flow cytometry. The first red line, the second oblique lines, and the third red-filled peak indicate the G0/G1, S, and G2/M phases, respectively.

ties of B-ADSCs were also stronger than those of W-ADSCs via ALnP and Oil-Red-O staining (Fig. 3E) as well as via mRNA expression levels of bone and adipose related genes (Fig. 3F).

\section{Stronger myocardial differentiation of B-ADSCs compared with W-ADSCs}

As is well-known, B-ADSCs could differentiate into cardiomyocyte. So we planted B-ADSCs and W-ADSCs on CNT and examined cardiomyocyte-related gene expression. The results showed that cardiomyocyte-specific markers cTnT and transcription factor GATA4 and Nkx2.5 expressed in B-ADSCs significantly more than those in W-ADSCs (Fig. 4A). This indicated that B-ADSCs did have increased myocardial differentiation capacity as compared to W-ADSCs. In aged mice, only transcription factor Nkx2.5 expressed in B-ADSCs significantly more than in W-ADSCs (Fig. 4B).

\section{Similar immunophenotype of ADSCs}

Many molecules such as PD-L1, VCAM-1, ICAM-1 and iNOS have been described to have major roles in MSC- mediated immunosuppression. To investigate the immunophenotype of ADSCs, we treated B-ADSCs and W-ADSCs with IFN- $\gamma$ and TNF- $\alpha$ at increasing concentrations, and left one group untreated. We found that PD-L1, VCAM-1, and ICAM-1 were significantly up-regulated in ADSCs that were stimulated with IFN- $\gamma$ and TNF- $\alpha$ at concentration of $2 \mathrm{ng} / \mathrm{ml}$, with no difference observed between B-ADSCs and W-ADSCs (Fig. 5A and 5B). However, PD-L1 was significantly up-regulated in W-ADSCs without stimulation than in B-ADSCs (Fig. $5 \mathrm{~A})$. We then compared the mRNA levels of representative inflammatory cytokines (iNOS, TNF- $\alpha$, IL10, socsl) between B-ADSCs and W-ADSCs by qRT-PCR. without stimulation, both B-ADSCs and W-ADSCs exhibited low levels of iNOS, TNF- $\alpha$, and socsl production; while with stimulation, their levels were elevated. However, there was no significant difference between B-ADSCs and W-ADSCs (Fig. 5C). We also compared the immunophenotype of B-ADSCs and W-ADSCs from aged mice, there was no significant difference (data not shown). Taken together, these results indicated that B-ADSCs and W-ADSCs have similar immunoregulation capacity. 




B
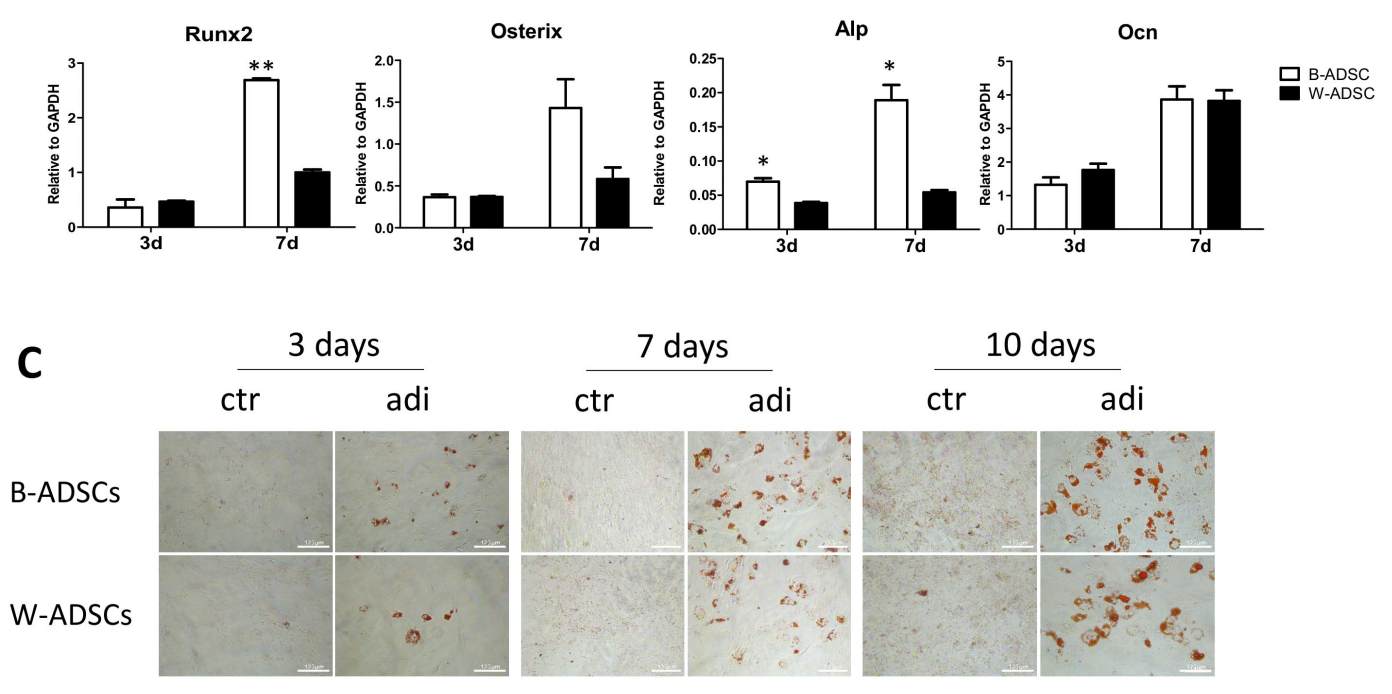

D
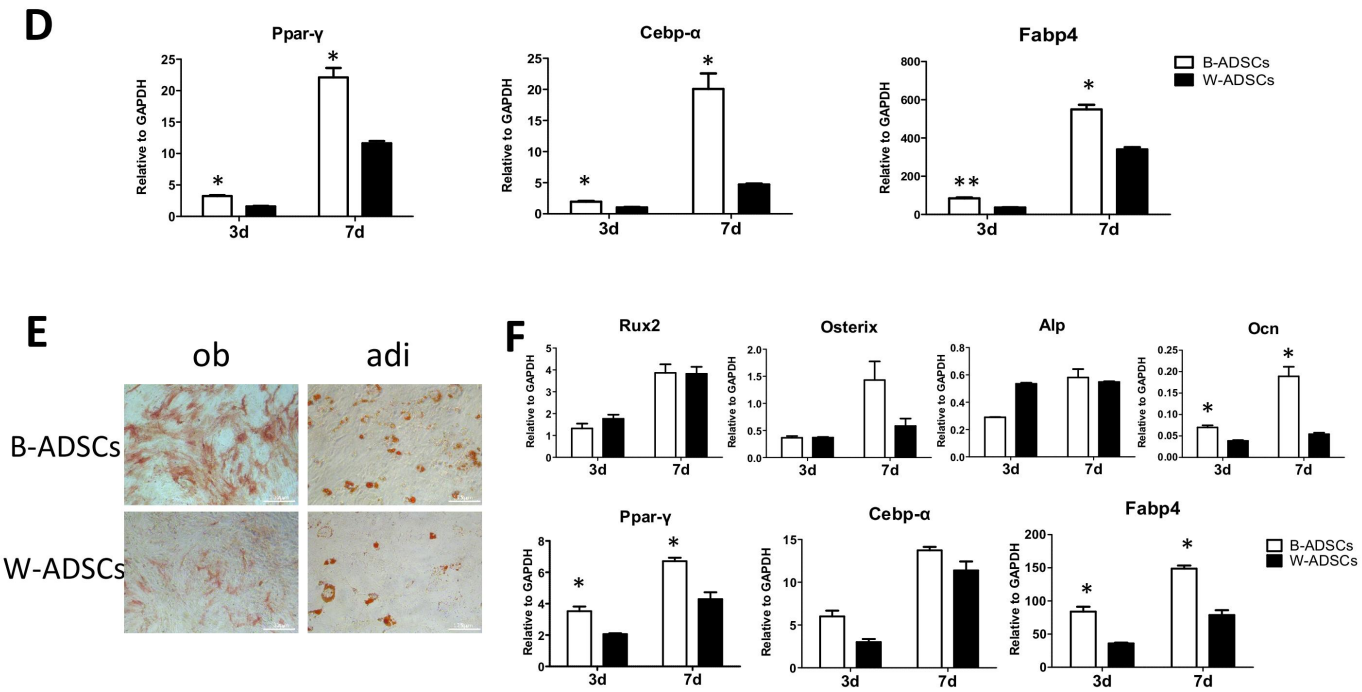

Fig. 3. Osteogenic and adipogenic differentiation capacity of B-ADSC and W-ADSC. ADSCs were cultured in osteogenic (A) and adipogenic (C) differentiation for different time points, and were stained with ALP (bar=250 $\mu \mathrm{m}$ ) or Oil Red O (bar=125 $\mu \mathrm{m})$. They were analyzed for Alp, Runx2, Ocn, Osterix (B), Ppar- $\gamma$, Cebp- $\alpha$, and Fabp4 (D) by qRT-PCR. (E) ADSCs of 7-to-8-month C57BL/6 mice were cultured in osteogenic or adipogenic medium for the indicated times, and were stained with ALP (bar=250 $\mu \mathrm{m})$ or Oil Red O (bar $=125 \mu \mathrm{m})$. They were analyzed for Alp, Runx2, Ocn, Osterix, Ppar- $\gamma$, Cebp- $\alpha$, and Fabp4 by qRT-PCR (F). (Three experiments were performed, and each experiment was observed three fields.) $* \mathrm{p}<0.05, * * \mathrm{p}<0.01$. 
A


B-ADSCs

W-ADSCs

B
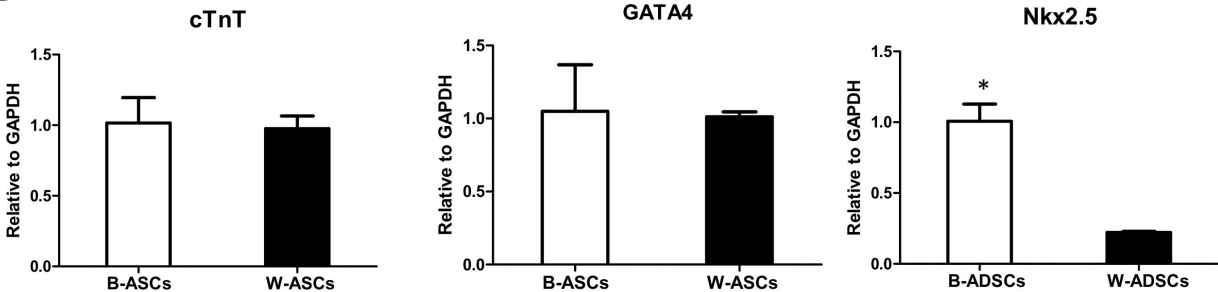

Fig. 4. Myocardial differentiation capacity of B-ADSCs and W-ADSCs. Cells from 3-to-4-week (A) and 7-to-8-month (B) C57BL/6 mice were cultured on carbon nanotube (CNT) for 3 days; cTnT, GATA4, and Nkx2.5 expression were examined by qRT-PCR. ${ }^{*} p<0.05,{ }^{* *}$ p $<0.01$.
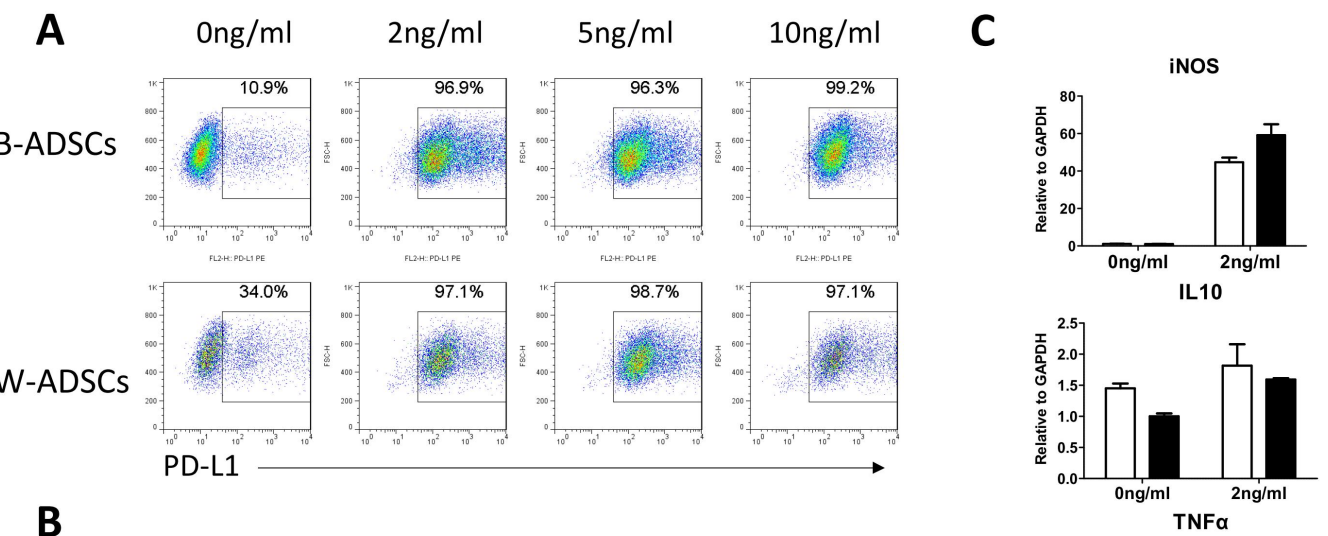

B
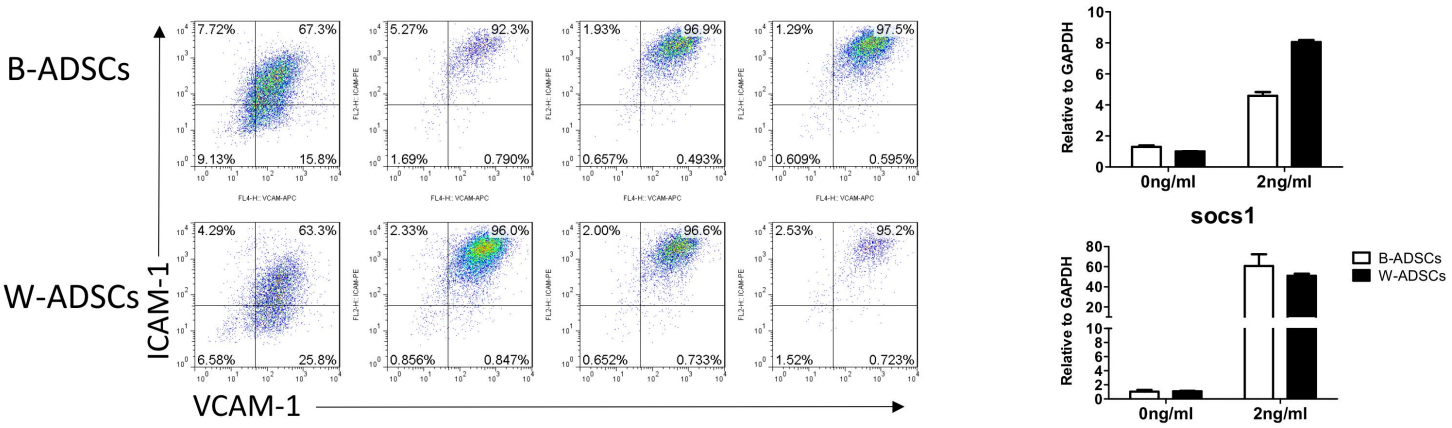

Fig. 5. B-ADSCs and W-ADSCs showed no significant effect on PD-L1, ICAM-1, and VCAM-1 expression under stimulation (representative of 3 experiments). B-ADSCs and W-ADSCs were cultured with stimulation of TNF- $\alpha$ and IFN- $\gamma$ at different levels $-0 \mathrm{ng} / \mathrm{ml}, 2 \mathrm{ng} / \mathrm{ml}$, $5 \mathrm{ng} / \mathrm{ml}$, and $10 \mathrm{ng} / \mathrm{ml}$ for 12 hours. The expression of PD-L1 (A), and ICAM-1 and VCAM-1 (B) were analyzed by flow cytometry. (C) B-ADSCs and W-ADSCs were cultured with stimulation of TNF- $\alpha$ and IFN- $\gamma$ at $0 \mathrm{ng} / \mathrm{ml}$ and $2 \mathrm{ng} / \mathrm{ml}$ for 12 hours. The expression of iNOS, IL10, TNF $\alpha$ and socs1 were examined by qRT-PCR. 


\section{Different immunoregulatory capacities of B-ADSCs and W-ADSCs from aged mice}

Next, to investigate whether the immunoregulation capacity of B-ADSCs and W-ADSCs in vitro were different, we selected $\mathrm{CD}^{+}{ }^{+} \mathrm{T} / \mathrm{CD}^{+}{ }^{+} \mathrm{T}$ cells which were labeled with CFSE, and stimulated them with PMA and ionomycin and co-cultured them with B-ADSCs and W-ADSCs, respectively. Changes in CFSE signals were then measured via flow cytometry to monitor $\mathrm{T}$ cell proliferation. We found that $\mathrm{T}$ cell proliferation was inhibited by both cells, which was indicated by a slower reduction in CFSE fluorescence intensity. Furthermore, a slight augment in $\mathrm{T}$ cell proliferation were observed in the one co-culture with W-ADSCs compared to the one co-culture with B-ADSCs at the highest ADSCs-to-T cell ratio. The data indicated that ADSCs reduced the proliferation of $\mathrm{CD}^{+}$(Fig. 6A) and $\mathrm{CD}^{+}$(Fig. 6B) T cells, but there was no significant difference between B-ADSCs and W-ADSCs in the immunoregulation capacity of young mice. However, B-ADSCs from aged mice showed lower immunosuppression to $\mathrm{CD}^{+}{ }^{+} \mathrm{T}$ cells than W-ADSCs at different ratio (ADSCs to $\mathrm{T}$ cell) (Fig. 6C).

\section{Discussion}

This is the first study to demonstrate that murine BADSCs have enhanced proliferation property and osteogenic, adipogenic and myocardial differentiation ability, but have no significant difference in immunoregulation capacity compared to murine W-ADSCs. However, these capacities of B-ADSCs and W-ADSCs change with age.

Adipose tissue is an attractive cell source for stem cell-based treatment because of its self-renewal and multipotential differentiation capacity as well as the ease to harvest in sufficient quantities (22). However, there are several regions around the body where adipose tissue is stored and can be used for isolation of ADCSs. It is confirmed that ADCSs from different regions of adipose tissue show different characteristics (23-25). Few studies have compared the differentiation and immunoregulation capacity of murine ADSCs from BAT and WAT, so the factors that affect these capacities are still unknown. Therefore, it is important and necessary to investigate which region is the best candidate for cell isolation and to understand whether age is an important factor to opti-
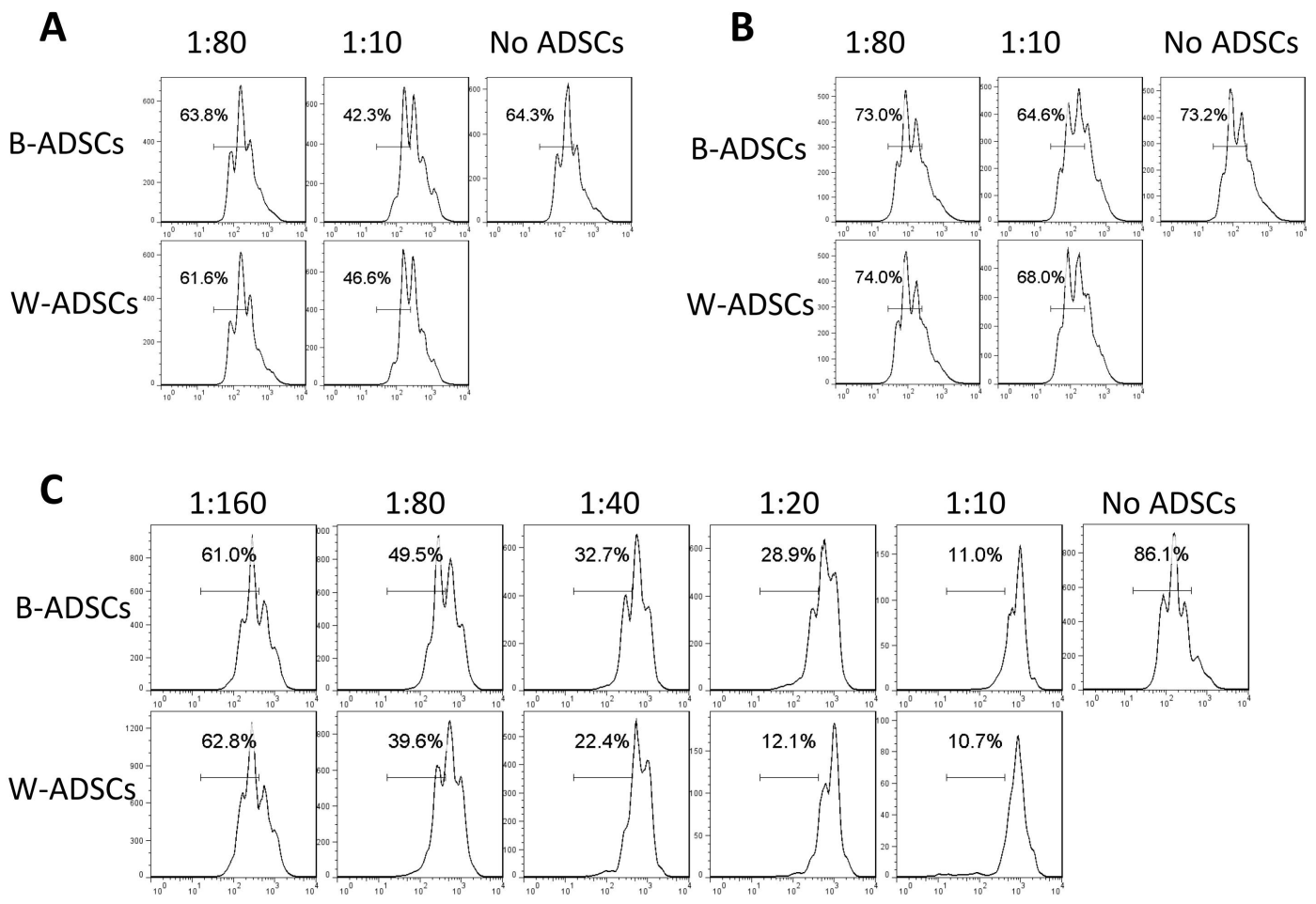

Fig. 6. Immunosuppressive capacity of B-ADSC and W-ADSC in vitro (representative of 3 experiments). CFSE-labeled CD ${ }^{+} \mathrm{T}$ cells (A) and $\mathrm{CD}^{+}{ }^{+} \mathrm{T}$ cells (B) were cultured alone or co-cultured with different numbers of ADSCs from 3-to-4-week C57BL/6 mice for 48 hours in RPMl 1640 complete medium, supplemented with PMA $(50 \mathrm{ng} / \mathrm{ml})$ and ionomycin $(1 \mu \mathrm{g} / \mathrm{ml})$. (C) CFSE-labeled CD3 ${ }^{+} \mathrm{T}_{\text {cells }}$ were cultured alone or co-cultured with different numbers of ADSCs from 7-to-8-month C57BL/6 mice. Cells were subjected to flow cytometry for $\mathrm{T}$ cell proliferation as detected by the CFSE signal. 
mize clinical applications and fundamental researches.

In this study, firstly we isolated B-ADSCs and WADSCs from interscapular adipose tissue and inguinal subcutaneous adipose tissue, respectively, and cultured successive passages from passage $0(\mathrm{P} 0)$ to passage 5 (P5). Our results revealed that both B-ADSCs and W-ADSCs showed spindle-shaped, fibroblast-like morphology and similar cell surface marker expression, which conformed to the characteristics of MSCs. Meanwhile, ADSCs from aged mice exhibited the same result. However, the proliferation of B-ADSCs was greater than W-ADSCs both in cell counting and cell-cycle phase assay, suggesting that the proliferating capacity of murine ADSCs is influenced by the harvesting region. Additionally, cell-cycle phase assay of B-ADSCs and W-ADSCs from elder mice also supported the above conclusion. What's more, a lot of evidence agrees with the role of the harvesting region as a crucial factor that influences cell proliferation rate (24, 26). In our in vitro differentiation experiment, B-ADSCs demonstrated an accelerated osteogenic and adipogenic capability compared with W-ADSCs, confirmed by ALP and Oil Red $\mathrm{O}$ staining, respectively. The same results were obtained in ADSCs from 7-to-8-month mice. In addition, B-ADSCs' significant enhanced osteogenic and adipogenic capability was confirmed by further mRNA expression levels analysis of bone related genes - namely, Alp, Runx2, Ocn, and osterix (27), and adipose related genes - namely, Ppar- $\gamma$, Cebp- $\alpha$, and Fabp4. This difference was also mentioned in a study by Ardeshirylajimi et al. (20), despite different species. Interestingly, we found B-ADSCs from young mice expressed higher levels of earlier phases of osteogenesis (Runx2 and Alp), while B-ADSCs from aged expressed higher levels of late osteogenesis genes, such as Ocn. This difference requires further study. All above indicated that cell-specific differences between B-ADSCs and W-ADSCs did influence the proliferation and osteogenic and adipogenic differentiation of cells.

It has been reported that adipose tissue contains stem cells that have the ability to differentiate into cardiomyocyte $(28,29)$. Therefore, we analyzed cardiac differentiation markers GATA4, Nkx2.5 (30) and cTnT mRNA expression of B-ADSCs and W-ADSCs. We found that the expression of cTnT and transcription factor GATA4 and Nkx2.5 in B-ADSCs were significantly more than those in W-ADSCs. However, only transcription factor Nkx2.5 expressed in B-ADSCs from aged mice was significantly more than in W-ADSCs. It suggested that B-ADSCs from young mice may be an appropriate candidate of the cell source for cardiomyocyte regeneration. Nonetheless, it requires more studies to understand whether myocardial dif- ferentiation of B-ADSCs attenuate with age.

To our knowledge, no report identifies the immunomodulation capacity between murine B-ADSCs and W-ADSCs. So we sought to determine if different results could be seen in the two cells from different regions. Several molecules such as PD-L1, ICAM-1, VCAM-1, iNOS and IL10 have been proposed in the mechanisms of immunosuppression by mouse MSCs (31-33). Our results showed that PD-L1 was up-regulated more significantly in W-ADSCs without stimulation than that in B-ADSCs, but this difference disappeared with the increase of stimulation concentration. The expression of ICAM-1 and VCAM-1 had no differences between BADSCs and W-ADSCs. It is important to note, B-ADSCs maybe show potential immunosuppression capacity and are needed further deep study. However, the expression of iNOS, IL10 and TNF- $\alpha$ showed no significant difference. Similarly, there was no difference between B-ADSCs and W-ADSCs in socs1, which controls signaling of many cytokines, including TNF- $\alpha$ and IL-10 with a feedback loop mechanism (34). In addition, in CFSE assay, both B-ADSCs and W-ADSCs inhibited the proliferation of $\mathrm{CD}^{+}$and $\mathrm{CD}^{+} \mathrm{T}$ cells as reported in many reports (35-37). Immunosuppression capacity to $\mathrm{T}$ cells between B-ADSCs and W-ADSCs had no significant difference. However, B-ADSCs from aged mice showed lower immunosuppression capacity to $\mathrm{CD}^{+} \mathrm{T}$ cells than W-ADSCs from aged mice.

Overall, this study identified the difference between murine B-ADSCs and W-ADSCs about their proliferation, differentiation and immunosuppression capacity. More importantly, these capacities would change with age. Hence, it provides new insights into the influence of ADSCs derived from different regions and ages, which would provide evidence for using tissue-specific ADSCs that are applicable for cell therapy and tissue engineering in murine species. Nonetheless, the deep molecular mechanisms of the difference still require further studied.

\section{Acknowledgments}

This work was supported by the National Natural Science Foundation of China (No. 81771998, No. 31971285 to XXJ; No. 51972339 to NW; No. 51802350 to LSZ).

\section{Potential Conflict of Interest}

The authors have no conflicting financial interest. 


\section{References}

1. Das M, Sundell IB, Koka PS. Adult mesenchymal stem cells and their potency in the cell-based therapy. J Stem Cells 2013;8:1-16

2. Bartholomew A, Sturgeon C, Siatskas M, Ferrer K, McIntosh K, Patil S, Hardy W, Devine S, Ucker D, Deans R, Moseley A, Hoffman R. Mesenchymal stem cells suppress lymphocyte proliferation in vitro and prolong skin graft survival in vivo. Exp Hematol 2002;30:42-48

3. Chamberlain G, Fox J, Ashton B, Middleton J. Concise review: mesenchymal stem cells: their phenotype, differentiation capacity, immunological features, and potential for homing. Stem Cells 2007;25:2739-2749

4. Glennie S, Soeiro I, Dyson PJ, Lam EW, Dazzi F. Bone marrow mesenchymal stem cells induce division arrest anergy of activated T cells. Blood 2005;105:2821-2827

5. Le Blanc K, Rasmusson I, Sundberg B, Götherström C, Hassan $M$, Uzunel $M$, Ringdén $O$. Treatment of severe acute graft-versus-host disease with third party haploidentical mesenchymal stem cells. Lancet 2004;363:1439-1441

6. Le Blanc K, Tammik L, Sundberg B, Haynesworth SE, Ringdén O. Mesenchymal stem cells inhibit and stimulate mixed lymphocyte cultures and mitogenic responses independently of the major histocompatibility complex. Scand J Immunol 2003;57:11-20

7. Zappia E, Casazza S, Pedemonte E, Benvenuto F, Bonanni I, Gerdoni E, Giunti D, Ceravolo A, Cazzanti F, Frassoni F, Mancardi G, Uccelli A. Mesenchymal stem cells ameliorate experimental autoimmune encephalomyelitis inducing T-cell anergy. Blood 2005;106:1755-1761

8. Friedenstein AJ, Deriglasova UF, Kulagina NN, Panasuk AF, Rudakowa SF, Luriá EA, Ruadkow IA. Precursors for fibroblasts in different populations of hematopoietic cells as detected by the in vitro colony assay method. Exp Hematol 1974;2:83-92

9. Zuk PA, Zhu M, Ashjian P, De Ugarte DA, Huang JI, Mizuno H, Alfonso ZC, Fraser JK, Benhaim P, Hedrick $\mathrm{MH}$. Human adipose tissue is a source of multipotent stem cells. Mol Biol Cell 2002;13:4279-4295

10. Bieback K, Kern S, Klüter H, Eichler H. Critical parameters for the isolation of mesenchymal stem cells from umbilical cord blood. Stem Cells 2004;22:625-634

11. In 't Anker PS, Scherjon SA, Kleijburg-van der Keur C, de Groot-Swings GM, Claas FH, Fibbe WE, Kanhai HH. Isolation of mesenchymal stem cells of fetal or maternal origin from human placenta. Stem Cells 2004;22:1338-1345

12. Lai D, Wang F, Dong Z, Zhang Q. Skin-derived mesenchymal stem cells help restore function to ovaries in a premature ovarian failure mouse model. PLoS One 2014;9: e98749

13. Yablonka-Reuveni Z, Day K, Vine A, Shefer G. Defining the transcriptional signature of skeletal muscle stem cells. J Anim Sci 2008;86(14 Suppl):E207-E216

14. Havasi P, Soleimani M, Morovvati H, Bakhshandeh B, Nabiuni M. The proliferation study of hips cell-derived neuronal progenitors on poly-caprolactone scaffold. Basic Clin Neurosci 2014;5:117-123

15. Huang GT, Gronthos S, Shi S. Mesenchymal stem cells derived from dental tissues vs. those from other sources: their biology and role in regenerative medicine. J Dent Res 2009; 88:792-806

16. Mizuno H. Adipose-derived stem cells for tissue repair and regeneration: ten years of research and a literature review. J Nippon Med Sch 2009;76:56-66

17. Katz AJ, Tholpady A, Tholpady SS, Shang H, Ogle RC. Cell surface and transcriptional characterization of human adipose-derived adherent stromal (hADAS) cells. Stem Cells 2005;23:412-423

18. Ra JC, Shin IS, Kim SH, Kang SK, Kang BC, Lee HY, Kim YJ, Jo JY, Yoon EJ, Choi HJ, Kwon E. Safety of intravenous infusion of human adipose tissue-derived mesenchymal stem cells in animals and humans. Stem Cells Dev 2011;20: $1297-1308$

19. Rosen ED, Spiegelman BM. Adipocytes as regulators of energy balance and glucose homeostasis. Nature 2006;444:847853

20. Ardeshirylajimi A, Rafeie F, Zandi-Karimi A, Jaffarabadi GA, Mohammadi-Sangcheshmeh A, Samiei R, Toghdory A, Seyedjafari E, Hashemi SM, Cinar MU, Gastal EL. Fat harvesting site is an important determinant of proliferation and pluripotency of adipose-derived stem cells. Biologicals 2016;44:12-18

21. Lim S, Honek J, Xue Y, Seki T, Cao Z, Andersson P, Yang $\mathrm{X}$, Hosaka K, Cao Y. Cold-induced activation of brown adipose tissue and adipose angiogenesis in mice. Nat Protoc 2012;7:606-615

22. Fraser JK, Wulur I, Alfonso Z, Hedrick MH. Fat tissue: an underappreciated source of stem cells for biotechnology. Trends Biotechnol 2006;24:150-154

23. Engels PE, Tremp M, Kingham PJ, di Summa PG, Largo RD, Schaefer DJ, Kalbermatten DF. Harvest site influences the growth properties of adipose derived stem cells. Cytotechnology 2013;65:437-445

24. Jurgens WJ, Oedayrajsingh-Varma MJ, Helder $M N$, Zandiehdoulabi B, Schouten TE, Kuik DJ, Ritt MJ, van Milligen FJ. Effect of tissue-harvesting site on yield of stem cells derived from adipose tissue: implications for cell-based therapies. Cell Tissue Res 2008;332:415-426

25. Kaewkhaw R, Scutt AM, Haycock JW. Anatomical site influences the differentiation of adipose-derived stem cells for Schwann-cell phenotype and function. Glia 2011;59:734749

26. Neupane M, Chang CC, Kiupel M, Yuzbasiyan-Gurkan V. Isolation and characterization of canine adipose-derived mesenchymal stem cells. Tissue Eng Part A 2008;14:10071015

27. Li P, Yang YM, Sanchez S, Cui DC, Dang RJ, Wang XY, Lin QX, Wang Y, Wang C, Chen DF, Chen SY, Jiang XX, Wen N. Deubiquitinase MYSM1 is essential for normal bone formation and mesenchymal stem cell differentiation. Sci Rep 2016;6:22211 
28. Planat-Bénard V, Menard C, André M, Puceat M, Perez A, Garcia-Verdugo JM, Pénicaud L, Casteilla L. Spontaneous cardiomyocyte differentiation from adipose tissue stroma cells. Circ Res 2004;94:223-229

29. Takahashi T, Nagai T, Kanda M, Liu ML, Kondo N, Naito AT, Ogura T, Nakaya H, Lee JK, Komuro I, Kobayashi Y. Regeneration of the cardiac conduction system by adipose tissue-derived stem cells. Circ J 2015;79:2703-2712

30. Olson EN. Gene regulatory networks in the evolution and development of the heart. Science 2006;313:1922-1927

31. Ren G, Zhao X, Zhang L, Zhang J, L'Huillier A, Ling W, Roberts AI, Le AD, Shi S, Shao C, Shi Y. Inflammatory cytokine-induced intercellular adhesion molecule-1 and vascular cell adhesion molecule-1 in mesenchymal stem cells are critical for immunosuppression. J Immunol 2010; 184:2321-2328

32. Sheng H, Wang Y, Jin Y, Zhang Q, Zhang Y, Wang L, Shen B, Yin S, Liu W, Cui L, Li N. A critical role of IFNgamma in priming MSC-mediated suppression of T cell proliferation through up-regulation of B7-H1. Cell Res 2008;18:846857
33. Xu C, Ren G, Cao G, Chen Q, Shou P, Zheng C, Du L, Han $X$, Jiang $M$, Yang $Q$, Lin L, Wang G, Yu P, Zhang $\mathrm{X}$, Cao W, Brewer G, Wang Y, Shi Y. miR-155 regulates immune modulatory properties of mesenchymal stem cells by targeting TAKl-binding protein 2. J Biol Chem 2013; 288:11074-11079

34. Kubo M, Hanada T, Yoshimura A. Suppressors of cytokine signaling and immunity. Nat Immunol 2003;4:1169-1176

35. Ahn JO, Chae JS, Coh YR, Jung WS, Lee HW, Shin IS, Kang SK, Youn HY. Human adipose tissue-derived mesenchymal stem cells inhibit T-cell lymphoma growth in vitro and in vivo. Anticancer Res 2014;34:4839-4847

36. Sato K, Ozaki K, Oh I, Meguro A, Hatanaka K, Nagai T, Muroi K, Ozawa K. Nitric oxide plays a critical role in suppression of T-cell proliferation by mesenchymal stem cells. Blood 2007;109:228-234

37. Wang $\mathrm{Y}$, Wang $\mathrm{X}$, Zhou $\mathrm{X}$, Zhu Z, Yang J, Liu F. Suppressive effect mediated by human adipose-derived stem cells on $\mathrm{T}$ cells involves the activation of JNK. Int J Mol Med 2019;43:177-184 